This document is the accepted manuscript version of the following article:

Allegrini, J., \& Lopez, B. (2016). The influence of angular configuration of two buildings on the local wind climate. Journal of Wind Engineering and Industrial Aerodynamics, 156, 50-61.

http://doi.org/10.1016/j.jweia.2016.07.008

This manuscript version is made available under the CC-BY-NC-ND 4.0 1icense

http://creativecommons.org/1icenses/by-nc-nd/4.0/

\title{
The influence of angular configuration of two buildings on the local wind climate
}

\author{
Jonas Allegrini ${ }^{\mathrm{a}, \mathrm{b}^{*}}$, Bruno Lopez ${ }^{\mathrm{c}}$ \\ ${ }^{a}$ Laboratory for Multiscale Studies in Building Physics \\ Swiss Federal Laboratories for Materials Science and Technology (Empa) \\ Überlandstrasse 129, 8600 Dübendorf, Switzerland \\ ${ }^{\mathrm{b}}$ Chair of Building Physics, Swiss Federal Institute of Technology Zurich (ETHZ), \\ Stefano-Franscini-Platz 5, 8093 Zürich, Switzerland \\ ${ }^{ }$Facultad de Ingeniería, Universidad de la República (UdelaR), \\ J. Herrera y Reissig 565, 11300 Montevideo, Uruguay
}

\section{Abstract}

Understanding flows in urban areas is important for a wide range of research areas. In this study the influence of different angular configurations of two buildings on the local wind climate is analysed. PIV (particle image velocimetry) measurements are conducted in an atmospheric boundary layer wind tunnel. Blocken et al. (Wind Environmental Conditions in Passages between Two Long Narrow Perpendicular Buildings. Journal of Aerospace Engineering 21 (4), 280-287, 2008) showed that, counterintuitively, the wind speeds in the passage of diverging configurations is higher compared to converging configurations. Blocken et al. focused on the wind climate at pedestrian level. The results of this new study show that from the ground to the roof level the wind speeds in the passage are increasing with increasing angles between the buildings for the converging cases, while they are decreasing for the diverging cases. For all cases the highest turbulent kinetic energies can be found downstream of the passage. For the converging cases these regions are located downstream of the buildings and mostly above the pedestrian level, while for diverging cases these regions are located between the buildings at the pedestrian level, where the probability that pedestrians are present is higher.

\section{Keywords}


1 wind tunnels, wind comfort, urban microclimate, Venturi effect, Particle Image Velocimetry (PIV),

2 boundary layer flow

Corresponding author: Jonas Allegrini, Empa Dübendorf, Ueberlandstrasse 129, 8600 Dübendorf, Switzerland. Tel.: +41 (0) 587656512 , Fax: +41 (0) 5876540 09, e-mail: jonas.allegrini@empa.ch

\section{Introduction}

Due to high building densities in urban areas, the wind in cities is often forced to flow in passages between buildings. Depending on the building configuration, the wind speed in the passage is increased or decreased, which has an influence on the (i) wind comfort, (ii) thermal comfort, (ii) pollutant dispersion, (iii) convective heat and mass transfer at building envelopes, (iv) wind-driven rain in urban areas and (v) wind loads on building façades. Furthermore, locations with increased wind speeds could have a potential for wind power generation. A large number of studies on flows in passages between buildings can be found in literature. Most of them focus on the pedestrian wind comfort. Mochida and Lun [1] and Blocken and Stathopoulos [2] present in their papers an overview of literature on pedestrian-level wind conditions around buildings.

Wiren [3] conducted wind tunnel measurements and found that wind speeds in passages between buildings are increasing with increasing building heights. His results also showed that wind speeds are higher, if the wind flows in a passage through a single building compared to the wind speeds in a passage with the same dimensions between two buildings. Beranek [4] studied the wind speed amplification for a large number of single building configurations and groups of buildings in a wind tunnel. Based on the large number of measurements he could derive some rules, which can predict the amplification for a number of different building configurations. Other wind tunnel studies on wind flows in passages between buildings were for example conducted by Stathopoulos and Storms [5] and Tsang et al. [6]. Dutt [7] conducted a field measurement and could also find overspeeds in passages between buildings at full scale. Besides wind tunnel and field measurements also CFD (Computational Fluid Dynamics) simulations have been conducted to study the wind flows between 
1 buildings. Stathopoulos [8] compared results from CFD simulations and wind tunnel studies for dif-

2 ferent cases. CFD studies with different building configuration were for example conducted by

3 Blocken et al. [9], Rizk and Henze [10], Tutar and Oguz [11] and Hong and Lin [12]. The winds in

4 urban areas are also important for ventilations. Asfour [13] studied, which configuration of four

5 buildings is optimal to increase the heat removal by wind to increase the passive cooling potentials

6 of the buildings. While increased wind speeds in urban areas have a negative impact on the wind

7 comfort of the pedestrians, they could be used for wind power generation. Awan et al. [14] showed

8 that small vertical axis wind turbines could be used to generate electricity in urban street canyons

9 with increased wind speeds. The potentials of wind power generation in urban areas or for single

10 high-rise buildings are discussed for example by Simoes and Estanqueiro [15] and Li et al. [16].

11 Kubilay et al. [17] studied the influence of local wind flow pattern between buildings on the wind driven rain impact on building facades. Due to the high complexity of the flow structures, it is difficult to drive general rules from the large number of studies on flow between buildings, which could be used by urban planners and architects to improve the urban microclimate. Reiter [18] summarized some of the most important flow phenomena in urban areas to be used for this purpose.

The increased wind speed in passages between buildings is often referred to as the Venturi effect (e.g. $[19,20])$. Blocken et al. [21] showed that, counterintuitively, the wind speeds are higher in diverging compared to converging building configurations with wind tunnel measurements, where they measured the wind speed at pedestrian height on the centre line in a passage between building models with a hot-wire anemometer. Blocken et al. [22] obtained similar results from CFD simulations, where they also showed that the air flow rates are higher in diverging compared to converging building configurations. Blocken et al. [21,22] explained this phenomenon by the fact that the Venturi effect was originally applied to flows in closed channels (Venturi [23]), whereas the flow between buildings involves an open domain. They showed that a large amount of the oncoming air is flowing over or around the buildings, what they call the wind-blocking effect [21, 22]. This block- 
1 ing is more pronounced for converging compared to diverging passages and therefore the wind

2 speeds are higher in diverging passages. Blocken et al. [21, 22] also compared the results of studies

3 from literature that were conducted for this kind of flows (mainly focusing on $[3,3,20]$ ) and found

4 that some conclusions of these studies seem to be contradicting. Li et al. [24] confirmed the results

5 by Blocken et al. [21, 22] with CFD simulations. Their results support the statement that the Venturi

6 effect is unsuitable to describe the outdoor passage flow with open boundaries. Also Li et al. [24]

7 focused on the pedestrian wind comfort, but they used a large number of different angles between

8 the buildings. They also found that the wind speeds in the passage between two buildings is de-

9 pendent on the drag coefficient of the buildings. Both Blocken et al. [22] and Lie et al. [24] deter-

10 mined flow rates (or fluxes) thought different planes to analyse, how much air is flowing over the

11 buildings and how much air is flowing through the passage between the buildings.

The results presented by Blocken et al. $[21,22]$ are limited to cases with a $90^{\circ}$ angle between the buildings, but they studied a large number of cases with different distances between the buildings, different building heights and wind directions. Li et al. [24] kept the distance between the buildings, the building heights and the wind direction constant, but varied the angle between the buildings.

In the study presented in this paper the flow in passages for parallel, side-by-side, converging and diverging building configurations with different angles between the buildings are measured. Compared to $\mathrm{Li}$ et al. [24] the distance between the buildings is smaller. Blocken et al. [21,22] and Li et al. [24] presented the wind speeds (almost) only at pedestrian level ( $2 \mathrm{~m}$ above the ground at fullscale). Blocken et al. [22] presents one vertical profile of the amplification factor in the narrowest passage between the buildings for different cases. Further also a schematic representation of the 3D flow is given in the paper. Here the results are analysed up to 2.5 times the building height. Blocken et al. [21] could only measure the velocity magnitude at a relative small number of locations. Flow fields with a higher spatial resolution can be measured with PIV compared with a hot-wire anemometer that was used by Blocken et al. [21]. Further with PIV there is the possibility to measure 
1 the two velocity components in a plane. The current study improves the understanding of the flow

2 structures of flows in passages between two buildings by presenting the flow field with high spatial 3 resolution in a vertical plane. Because of this higher resolution, the results presented in this paper could be also used for more detailed validation of numerical simulations compared to the validation conducted by for the CFD studies mentioned above. Additionally to what was already analysed in literature (e.g. $[21,22,24])$, vertical wind speeds in the passage between the buildings (instead of flow rates at roof height), streamlines in a vertical plane, the turbulent kinetic energies and Reynolds stressed are studied in detail in this paper. Further in contrast to other studies (e.g. [21, 22, 24]), this paper does not focus on the wind speeds at pedestrian level, but presents wind speeds for all distances above the ground (up to 2.5 times the building height). Theoretically most of this information could be extracted from the CFD simulations by Blocken et al. [22] and Li et al. [24], but was not presented in their papers. Instead they both presented flow fields on a horizontal plane at pedestrian height.

In this study the flow in a passage between two buildings with different angular configurations is measured. No surrounding buildings are considered and therefore this configuration does not represent an urban environment. In urban environments neighbouring buildings can have a strong impact on the flow in the surrounding areas (presented e.g. in [25] and [26]). Therefore the flow in the passage between the two studied buildings could strongly vary depending on the geometries of the neighbouring buildings. Here the flow between the two buildings was measured in a stand-alone configuration to get more general conclusions. To study the flow between the two buildings in a specific urban area, additional measurements have to be conducted. Comparing these results with the results of this study, it could be analysed, which effects are caused by the configuration of the two buildings and what are the impacts of neighbouring buildings.

The structure of the paper is as follows. The details of the used wind tunnel, the measurements system and the model geometries are given in Section 2. In Section 3 the results of the wind tunnel 
1 measurements are given. In a first part the measured wind speeds are presented and discussed and in

2 a second part the results of the measured turbulence are given. In Section 4 it is discussed, which

3 additional measurements could be conducted to study flows in urban areas for a wider range of con-

4 figurations and in Section 5 the conclusions from the results of this study are drawn.

\section{2. Experimental setup}

\section{$6 \quad 2.1$ Experimental facility and measurement system}

7 This study was conducted in the closed circuit ETH/Empa atmospheric boundary layer wind tunnel 8 in Dübendorf (Switzerland). The test section is $1.9 \mathrm{~m}$ wide and $1.3 \mathrm{~m}$ high. For the PIV measure9 ments, the flow is seeded with $1 \mu \mathrm{m}$ DEHS (Di-Ethyl-Hexyl-Sebacat) aerosol particles. The PIV images are acquired with a 12 bit CMOS camera. The camera has a maximum resolution of $2016 \mathrm{x}$ 2016 pixels. During the measurements the images are stored locally on a 36 GB memory on the camera. At full resolution 3155 double-frame images can be stored on the camera. The maximum recording at full camera resolution frequency is $640 \mathrm{~Hz}$. The camera is equipped with a $135 \mathrm{~mm}$ F2.0 Canon objective. For the illumination a diode-pumped Q-switched dual-cavity Nd:YLF laser with a wavelength of $527 \mathrm{~nm}$ and a maximum energy per pulse of $30 \mathrm{~mJ}$ (at $1 \mathrm{kHz}$ repetition rate) is used. The image acquisition and planar PIV vector processing are performed with the software DaVis 8 from LaVision $\mathrm{GmbH}$.

In total, 3155 double-frame images were recorded at $10 \mathrm{~Hz}$ to obtain reliable time-averaged flow field statistics. The separation time between the two frames was $150 \mu \mathrm{s}$. The PIV processing was performed using a multi-pass approach and a final interrogation window of 24 pixels, with a $50 \%$ window overlap.

Best practice guidelines for PIV [27, 28, 29] were taken into account to reduce the measurement uncertainties. The camera calibration was performed with a $200 \mathrm{~mm}$ x $200 \mathrm{~mm}$ calibration plate. The camera and lens parameters were calculated by fitting a polynomial function to the calibration 
1 images. The reported standard deviation of the fit was 0.2 pixels. The uncertainty of the measurements was determined by performing the analysis recommended by ITTC [30]. The uncertainty was estimated to be $2-8 \%$ depending on the local wind speed.

4

5

6

\subsection{Model Geometry}

Two transparent, glass building models were used for this study to be able to measure the flow in between the buildings with PIV by ensuring optical access there. The models were made out of five $4 \mathrm{~mm}$ thick glass panes (no pane at the bottom), which were glued together at the edges. The glass models were $2.5 \mathrm{~cm}$ wide $(\mathrm{W}), 7.5 \mathrm{~cm}$ high $(\mathrm{H})$ and $25 \mathrm{~cm}$ long $(\mathrm{L})$. At the edges of the buildings, the thick glass panes block part of the view from the camera to the flow. Therefore the flow field cannot be measured in those areas. The models were carefully cleaned before each measurement. Dust particles on the glass strongly reflect diffuse laser light. Therefore no PIV measurements are possible at the locations of the dust particles. For some cases not all dust particles could be removed and therefore some regions with erroneous velocity vectors can be seen in the results. The building models had the same dimensions as the models used by Blocken et al. [21, 22] and Li et al. [24] following a scale of 1:400. Blocken et al. [21] chose those dimensions, because Gandemer [19] mentioned that these dimensions would lead to a Venturi effect for converging configurations.

In this paper the influence of different angular configurations of the two buildings was studied. The types of angular configurations are given in Figure 1: (i) diverging, (ii) converging, (iii) parallel and (iv) side-by-side. The smallest distance between the buildings was $2.5 \mathrm{~cm}$ (D) for all configurations. This corresponds to the smallest distance that Blocken et al. [22] used in their measurements. And the distance to building height ratio $(\mathrm{D} / \mathrm{H})$ is three times smaller compared to the ratio used by Li et al. [24]. For the diverging and converging cases three angles between the buildings were used: $60^{\circ}$, $90^{\circ}$ and $120^{\circ}\left([24]\right.$ additionally simulated $30^{\circ}$ and $\left.150^{\circ}\right)$. 

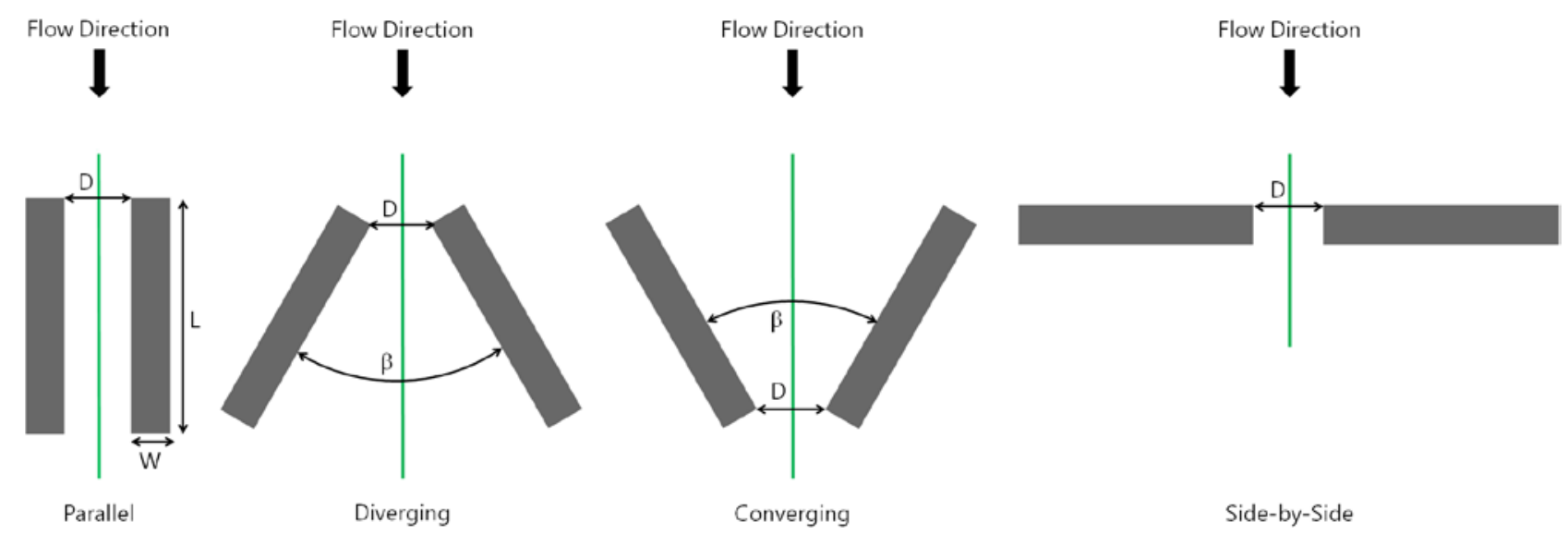

Figure 1: Different angular building configurations ( $\beta$ : angle between the buildings, D: distance between the buildings in the narrowest passage, L: building length, W: building width). The green line indicates the light sheet position for the PIV measurements.

The light sheet was positioned in the centre of the wind tunnel test section. The field of view for the PIV measurements was about $21 \times 21 \mathrm{~cm}^{2}$. To be able to measure the flow upstream, between and downstream of the buildings, three PIV measurement planes were measured for each case (except for the case "side-by-side"). A first measurement was conducted with the narrowest passage (diverging and converging cases) approximately in the centre of the field of view. For the second measurement the buildings were moved $15 \mathrm{~cm}$ to measure the flow in between the buildings and for the third measurement the light sheet was moved $15 \mathrm{~cm}$ downstream to measure the flow downstream of the buildings. Finally the results were stitched together for the analysis. The building models could be moved, because the boundary layers did not strongly change in flow direction (discussed in the following section).

To create a scaled atmospheric boundary layer (ABL), four $120 \mathrm{~cm}$ tall Irwin-type spires (at the bottom $10 \mathrm{~cm}$ wide) [31], a $5 \mathrm{~cm}$ barrier with $5 \mathrm{~cm}$ castellation and roughness elements consisting of Lego blocks (11.3 mm high) and Lego baseplates were installed in the wind tunnel (Figure 2). The dimensions of the different elements were chosen according to the guidelines of Counihan [32] (with some small modifications). The distances between the different elements are given in Figure 2 as well as the configuration of the Lego blocks on the Lego baseplates. No roughness elements were 
1 placed around the building models. The last roughness element was placed $113.9 \mathrm{~cm}$ upstream of

2 the centre of the PIV images. The created ABL does not follow the characteristics of a specific ABL

3 that was measured in a field measurement. For this study a realistic ABL was needed, but not an ex-

4 isting ABL. For all measurements the same wind speed and wind direction (indicated in Figure 1)

5 were used.

a)

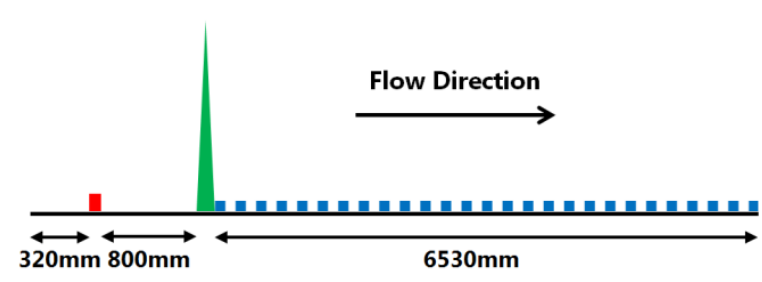

b)

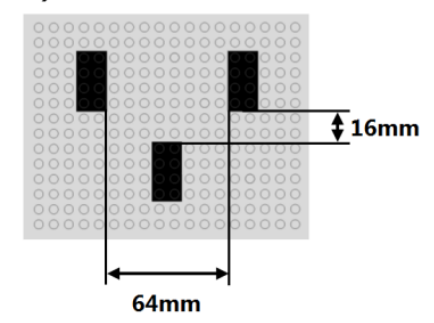

7 Figure 2: Sketch of the different elements (barrier, spires and roughness elements) to create the ABL and the distances between the different elements (a). Positions of the Lego blocks on the Lego baseplates (b).

\section{Results}

\subsection{Boundary Layer Profiles}

First the boundary layer profiles are measured at the location, where the building models are placed for the experimental study. The boundary layer profiles are measured from the wind tunnel floor to $8.8 \mathrm{H}$ above the floor to be able to determine the exponent of the power law function, which is commonly used to approximate ABL. Four PIV measurements are conducted and stitched to get the ABL profiles. For the measurements of the flow around the buildings the field of view of the PIV 
measurements only extends up to $2.8 \mathrm{H}$ above the wind tunnel floor. In Figure 3, the boundary layer profiles are given as well as the horizontal profiles of the time averaged wind speed and turbulence intensity in streamwise direction. The wind speeds and turbulence intensities are normalized by the values measured without the buildings at roof height at the position of the narrowest passage between the buildings $\left(\mathrm{U}_{\text {ref }}=3.01 \mathrm{~m} / \mathrm{s} ; \mathrm{I}_{\text {ref }}=11.5 \%\right.$ ). The building Reynolds-number is $15^{\prime} 200$ (using $\mathrm{U}_{\text {ref }}$ and building height $\mathrm{H}$ ), what is above the critical Reynolds-number according to Snyder [33].
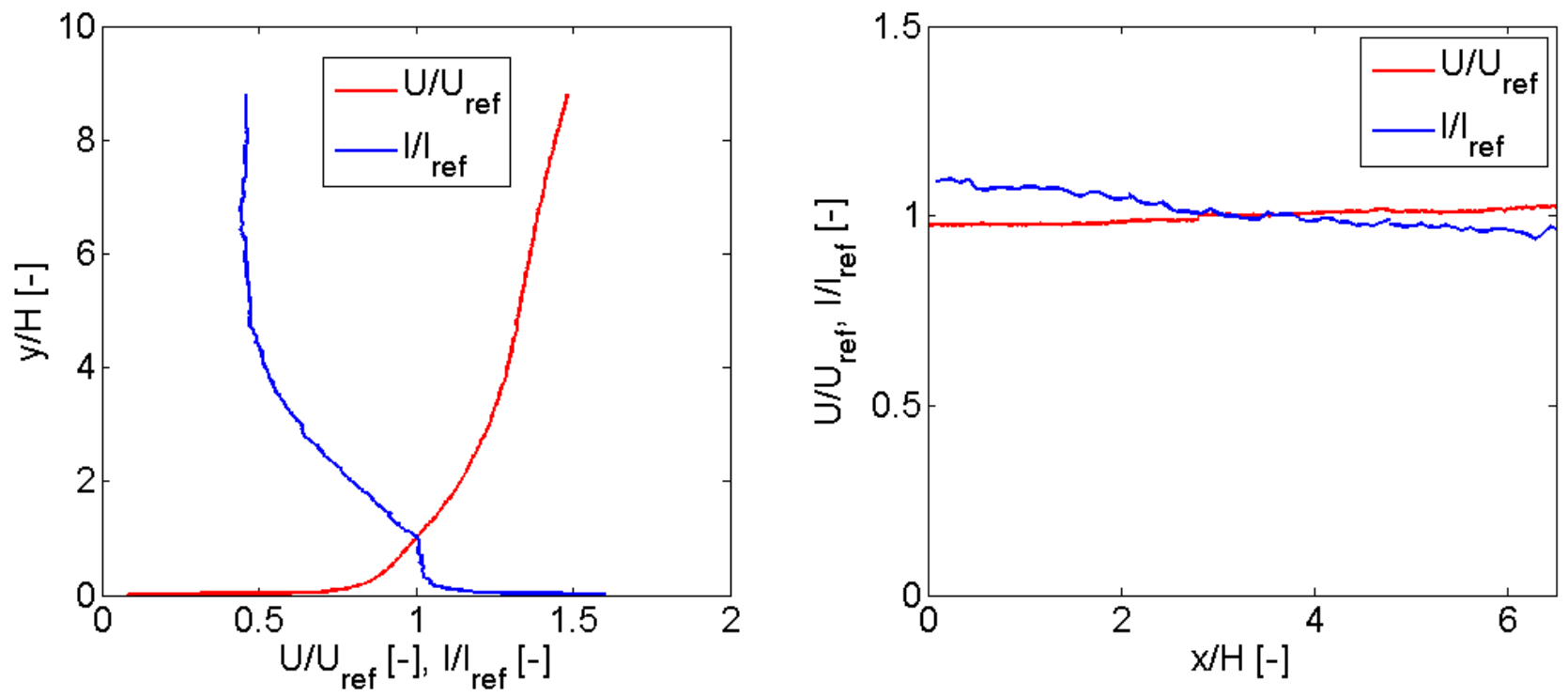

Figure 3: Boundary layer profiles of normalized wind speed and the normalized turbulence intensity at the position of the narrowest passage between the two buildings (left). The wind speeds and turbulence intensity are normalized by $\mathrm{U}_{\text {ref }}$ and $\mathrm{I}_{\text {ref }}$ respectively; Horizontal profiles of the normalized wind speed and normalized turbulence intensity in streamwise direction at roof height (right).

The upper region of the wind speed profiles can be approximated with a power-law function. A value of the exponent $\alpha=0.15$ was obtained from the fitting, and it was inferred that the power-law region begins slightly above $0.5 \mathrm{H}$. The turbulence intensity profile has the shape of an atmospheric boundary layer. The turbulence intensity in the boundary layer is between $5 \%$ and $15 \%$. The profiles correspond to a moderately rough atmospheric boundary layer [34]. Such boundary layers could be found for grassland or farm land. There is only a small increase of the wind speed in the streamwise direction. The decrease of the turbulence intensity is a bit larger. These changes are 
1 small and do not influence the flow field around and between the buildings. This is also confirmed

2 by the fact that the flow fields presented in the following section can be stitched, although the models were moved in streamwise direction between the individual measurements.

4 For this study the same building geometries are used as Blocken et al. [21] used for their measurements, but the measurements were conducted in a different ABL wind tunnel with a similar ABL profile. The ABL profile in the wind tunnel used by Blocken et al. [21] had a power law exponent of 0.125 , what is rather similar to the exponent of this study. The turbulence intensity in the ABL in the study of this paper is higher. Also the turbulence intensities are similar close to the wind tunnel floor, but in the study of this paper the turbulence intensity remain constant up to about $\mathrm{H}$, while the turbulence intensity in the study of Blocken et al. [21] starts to decrease just above the wind tunnel floor. Also higher above the wind tunnel floor the two ABL converge to different turbulence intensities (lower in the case of Blocken et al. [21]).

\subsection{Flow in the Passage between two Buildings}

\subsubsection{Velocity magnitudes}

The main aim of this paper is to study the wind speed between two buildings with different angular configurations. Therefore first the velocity magnitudes between the buildings are presented. Figure 4 shows the normalized wind speeds on the symmetry plane between the two buildings for all 8 studied cases. Additionally also the streamlines are given in the figures. The wind speed is normalized by the value measured without the buildings at roof height at the position of the narrowest passage between the buildings $\left(\mathrm{U}_{\mathrm{ref}}\right)$. In some regions in the figures no velocity vectors could be determined. These regions are mainly at the edges of the buildings and in regions, where small dust particles were on the glass panes. These regions are mostly blue and are not removed from the figures because they give a reference for the building positions. The results show that for all cases the highest wind speeds can be found just downstream of the narrowest passage. For all converging cases the wind speeds in the passage is smaller compared to the diverging cases with the same angle be- 
1 tween the buildings at all heights above the ground confirming the results reported by Blocken et al.

$2[21,22]$ and Li et al [24] at the pedestrian level.
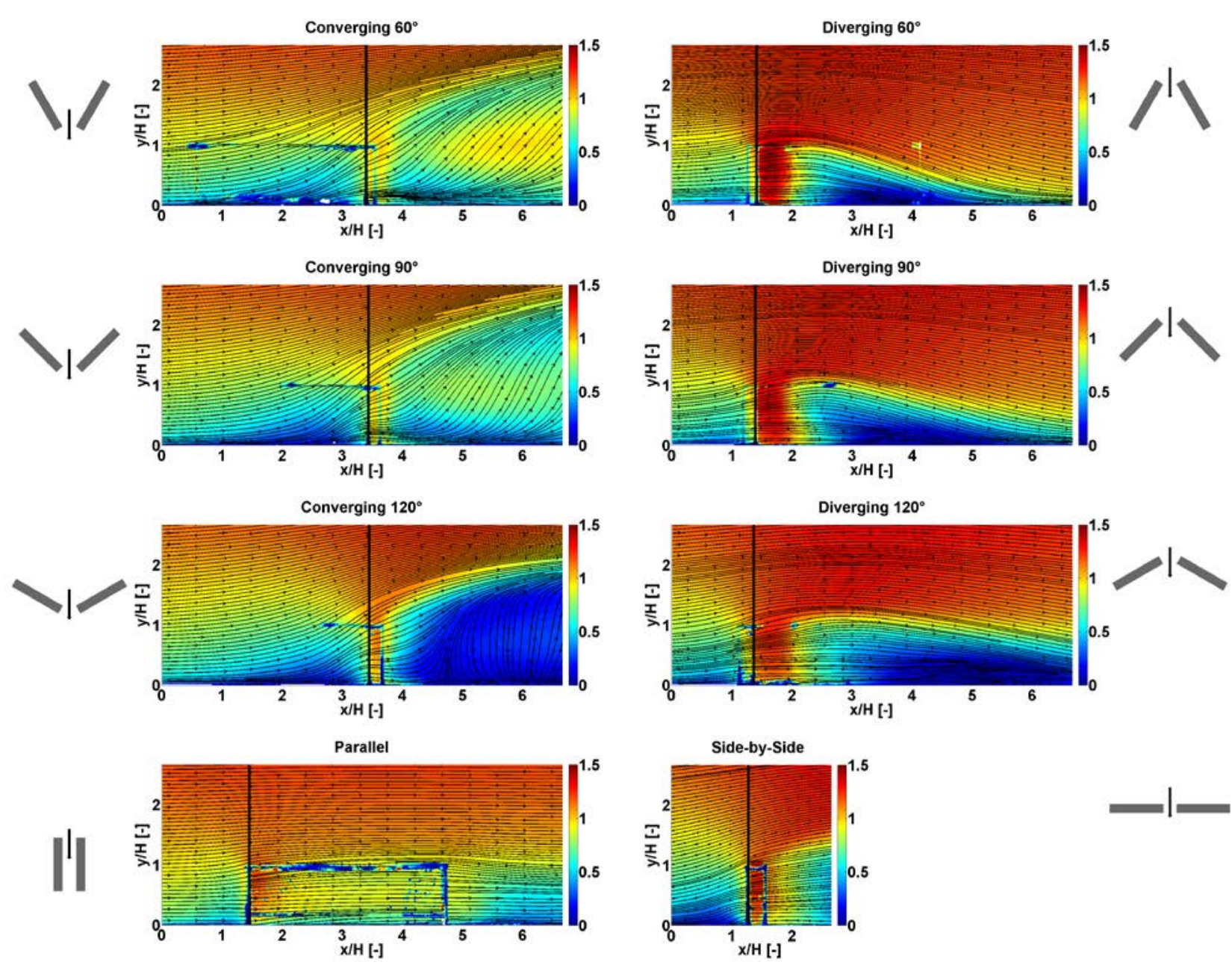

3

Figure 4: Normalized wind speeds and streamlines for all eight studied cases. The wind speeds are normalized by $\mathrm{U}_{\text {ref. }}$ The black line indicates the position of the narrowest passage between the buildings.

At all heights above the wind speed in the passage is increasing for larger angles between the buildings for the converging cases, while for the diverging cases the wind speed is increasing when the angle between the buildings reduces. Assuming that the flow patterns could be explained solely with the Venturi effect would mean that all the air that is entering the region between the buildings would have to flow through the passage between the buildings (already explained by Blocken et al. $[21,22])$. With this assumption the wind speed in the narrowest passage could be determined with the continuity equation. But the streamlines in Figure 4 show that for all cases a large part of the air 
1 is flowing over the passage and not through it, what makes the prediction of the wind speeds in the

2 passage more complex. For the converging cases more air is flowing over the passage compared to

3 the diverging cases, what explains the lower wind speeds in the passage for the converging cases

4 (see also Figure 7). The same phenomena was already found by Blocken et al. [21, 22] by analysing

5 the air flow rates at roof height instead of studying vertical wind speeds or analysing streamlines.

6 Also the higher wind speeds for larger angles for the converging cases and the lower wind speeds

7 for larger angles for the diverging cases can partly be explained by the differences in vertical wind

8 speeds and therefore higher flow rates of air over the two buildings. Additionally there are 3D ef-

9 fects, which might explain these results. These 3D effects could not be measured with the planar PIV system used for this study. Downstream of the buildings there is a region with low wind speed for all cases. For large angles between the buildings this region is larger due to the higher blockage of the flow. For the converging cases there are strong upwards motions downstream of the buildings, which are stronger for larger angles between the buildings. These are probably cause by threedimensional vortex structures that are formed at the building edges. The parallel and side-by-side cases have wind speeds in the passage, which are similar to the wind speeds of the diverging cases what is shown by the streamlines. For the side-by-side case the upwards motions are stronger due to the larger blockage.
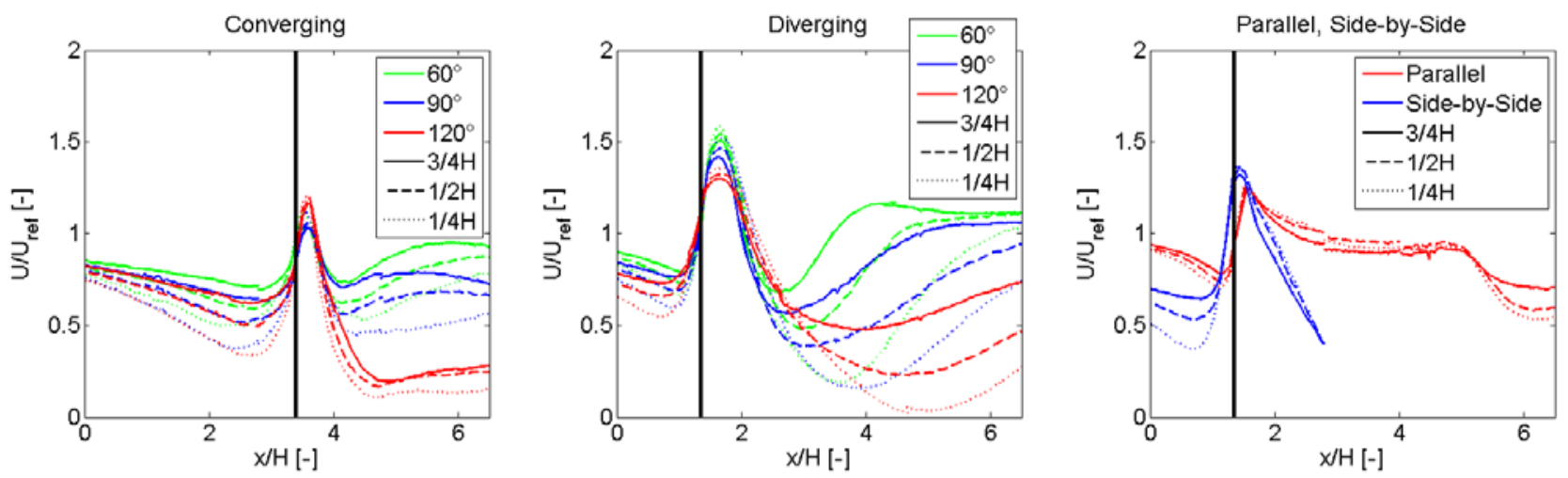
Figure 5: Horizontal profiles of the normalized wind speeds at three heights above the ground for all eight cases. The velocities are normalized by the velocities measured in the ABL at the corresponding heights above the ground (1/4H: $2.6 \mathrm{~m} / \mathrm{s} ; 1 / 2 \mathrm{H}: 2.8 \mathrm{~m} / \mathrm{s} ; 3 / 4 \mathrm{H}: 2.93 \mathrm{~m} / \mathrm{s})$. The vertical line indicates the position of the narrowest passage.

Horizontal profiles of the normalized wind speeds at different heights above the ground are given in Figure 5 to study the flows in more detail. The wind speeds are normalized with the wind speed without buildings at the same heights, which are presented in Figure 3. These profiles show that for all heights above the ground the highest wind speeds in the passage between two buildings are higher for diverging compared to converging configurations for the same angle between the two buildings (already presented by Blocken et al. [21, 22] and Li et al. [24] for pedestrian level). The normalized wind speeds up- and downstream of the narrowest passage are almost everywhere below 1 . Only in the narrowest passage they are above 1 for all cases. This shows a significant speed up of the flow between the buildings and means that for all studied cases the wind speeds in the narrowest passage are higher compared to the wind speeds at the same heights in the ABL without buildings. Upstream of the buildings the wind speeds are lower for configurations with larger angles between the buildings (also for the side-by-side case). Downstream of the narrowest passage the wind speeds decrease faster and the regions of low speeds behind the buildings are larger for cases with larger angles between the buildings. For the diverging cases the wind speed is increasing again after the strong decrease. The increase is stronger for smaller angles between the buildings, because more air with higher momentum is entering the region between the buildings from above. For all cases the normalized wind speeds closer to the ground are lower. This effect is stronger for the diverging compared to the other cases in the passage and downstream of the buildings. For the parallel and side-by-side cases these differences are smaller, because the flow is almost parallel to the ground and therefore the shape of the boundary layers is similar to the ABL profile.

The results in this section show that the wind speeds between two buildings with converging configurations are lower compared to diverging configurations for all studied heights above the ground 
1 and all studied angles between the buildings. This was already shown by Blocken [21, 22] at the

2 pedestrian level for $90^{\circ}$ angles between the buildings and by Li et al. [24] at the pedestrian level

3 with different angles between the buildings, but a different ratio between the passage width and the

4 building height $(\mathrm{D} / \mathrm{H})$. The higher wind speeds for the diverging configurations at the higher parts

5 of the buildings could increase the local potential for wind power generation.

\subsubsection{Horizontal wind speeds}
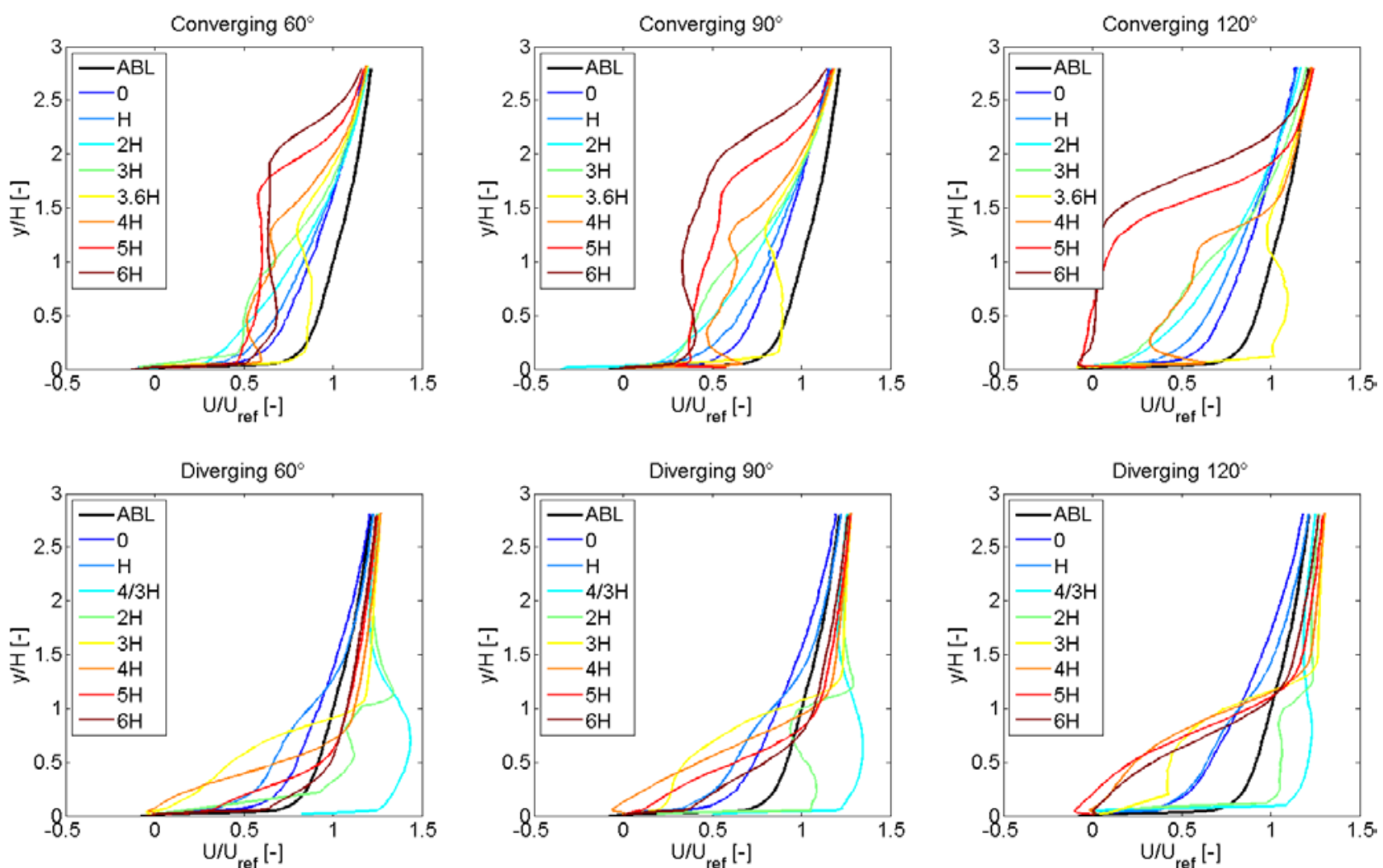

Figure 6: Vertical profiles of the normalized horizontal velocity at 8 downstream positions for six cases. The velocities are normalized by $\mathrm{U}_{\text {ref. }}$ Additionally the ABL profile is given.

After analysing the velocity magnitude in the previous section, the horizontal velocities are studied in this section. Figure 6 shows the vertical profiles of the horizontal velocity for all 6 converging and diverging cases at different downstream positions. The velocities are normalized by $\mathrm{U}_{\text {ref. }}$ Additionally the ABL profiles are given to be compared with the local boundary layers for the different studied cases. For the converging cases a larger number of profiles are given for positions upstream 
1 of the narrowest passage compared to the diverging cases. This is due to the fact that the focus of

2 this study is mainly on the regions between the buildings and these regions are upstream of the narrowest passage for the converging cases and downstream of the narrowest passage for the diverging cases. For all cases the horizontal velocities are mostly lower for the cases with buildings compared to the ABL. At $2.5 \mathrm{H}$ above the ground the horizontal velocities are very similar to the velocities in the ABL for all cases. Therefore the influence of the buildings on the flow only extends up to about $2.5 \mathrm{H}$ above the ground.

Upstream of the narrowest passage the shape of the boundary layer profiles are very similar to the ABL profile for all cases, but the horizontal velocities are decreasing in flow direction. The highest horizontal velocities can be found for all cases on the closest downstream position from the narrowest passage (converging cases: $3.6 \mathrm{H}$, diverging cases: $4 / 3 \mathrm{H}$ ). Not only the velocities are increased, but also the shapes of the profiles change compared to the upstream positions. The horizontal velocities are rather constant from the ground to the roof height $(\mathrm{H})$ and do not have the shape of a ABL anymore. As already discussed for Figure 4, the horizontal velocities have similar shapes after the narrowest passage for the different cases, but lower wind speeds for the converging profiles change after a short distance downstream of the narrowest passage. The horizontal velocities close to the ground are decreasing strongly (at some positions even get negative close to the ground) and are then slowly increasing again in flow direction.

The results of Figure 6 show that the wind speeds between to buildings in diverging or converging setups are mostly lower compared to the ABL without buildings. Only in the narrowest passage the wind speeds might be higher, what could lead to decreased thermal and wind comfort, but also to 
1 increased potentials for local power generation. The shapes of the velocity profiles strongly change

2 close to the narrowest passage between the buildings. In both cases, the horizontal velocities

\subsubsection{Vertical wind speeds}

10

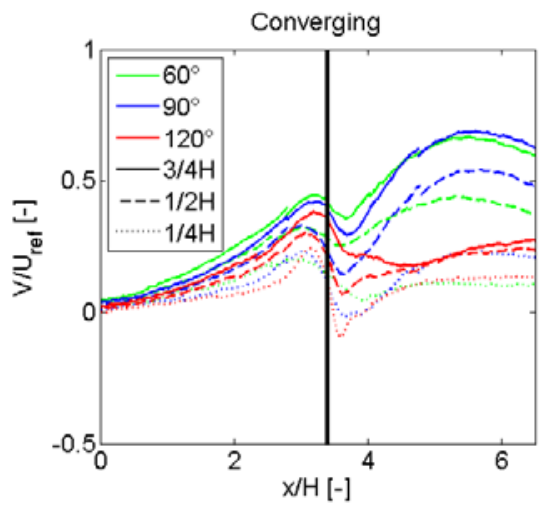

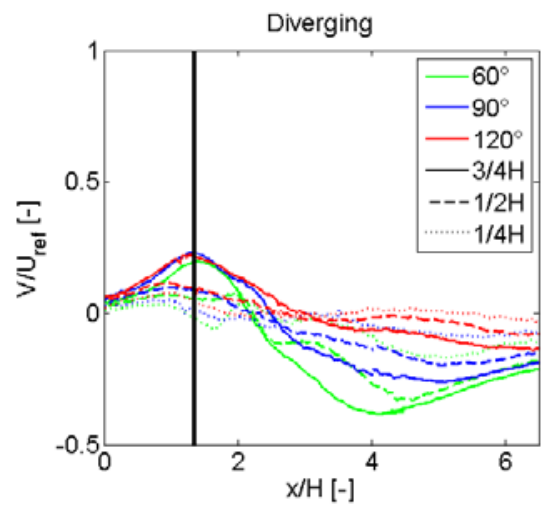

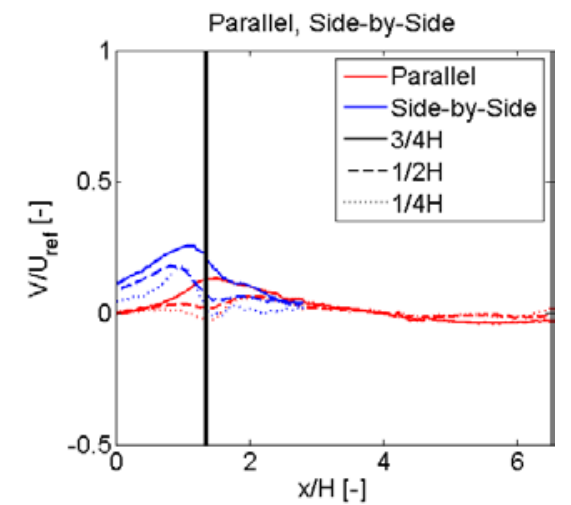

Figure 7: Horizontal profiles of the normalized vertical velocity at three heights above the ground for all eight cases.

The velocities are normalized by $U_{\text {ref. }}$ The vertical line indicates the position of the narrowest passage.

Above it was already discussed multiple times that the wind speeds in the narrowest passages are not as high as it could be assumed, because a part of the air is flowing over the buildings instead of through the passage between the buildings. This effect was first reported by Blocken et al. [21, 22], who used the term wind-blocking effect to descript this effect. In this section the vertical velocity components are analysed in more detail to study this effect. Blocken et al. [22] studied this effect by analysing flow rates (or fluxes) and could confirm that its existence. Here this effect is studied by analysing the vertical velocity components. In Figure 7 horizontal profiles of the vertical velocity are given for all eight cases for different heights above the ground. The velocities are normalized by 
$1 \mathrm{U}_{\text {ref }}$ to be able to compare the vertical velocities with the velocity magnitudes found in the ABL.

2 This gives information on the importance of the vertical velocities on the flow.

3 The horizontal profiles are very different for the four different studied configurations (converging,

4 diverging, parallel and side-by-side). The converging cases have at all heights above the ground the

5 strongest upwards motions of all four configurations. These upwards motions increase upstream of

6 the narrowest passage, confirming what Blocken et al. [22] found analysing flow rates. Due to these

7 upwards motions a part of the air is flowing over the buildings and therefore the Venturi effect is

8 not as strong as it could be assumed. For smaller angles between the two buildings the upwards mo-

9 tions are stronger and therefore more air is flowing over the buildings, what partly explains the lower wind speeds in the narrowest passage for the cases with smaller angles between the buildings. Just after the narrowest passage the upwards motions are decreasing. But further downstream the upwards motions are increasing again and the peak is in the wake of the buildings. These strong upwards motions are assumed to be caused by three-dimensional vortex structures. The upwards motions are in general stronger with increasing distance from the ground.

For the diverging cases the vertical velocities are smaller compared to the converging cases. This means that less air is flowing over the buildings and more air could flow through the narrowest passage between the buildings. This could not been shown by the analysis using flow rates conducted by Blocken et al. [22] and Li et al. [24]. A reason for the weaker upwards motion is the smaller effect of the blockage due to the buildings on the flow upstream of the narrowest passage. The vertical velocities are strongly increasing with distance from the ground for the diverging cases. After the narrowest passage the upwards motions are decreasing and downwards motions can be found further downstream. Here the downstream motions are stronger with increasing distance from the ground. Finally further downstream the downwards motions are decreasing again. 
1 For the parallel configurations there are no strong vertical motions. In the region of the narrowest

2 passage some upwards motion can be found. Further away from the passage (upstream and down-

3 stream) the flow is rather parallel to the ground. For the side-by-side configuration the upwards mo-

4 tions upstream of the passage can be found. These upwards motions decrease strongly after the pas-

5 sage and flow gets parallel to the ground again.
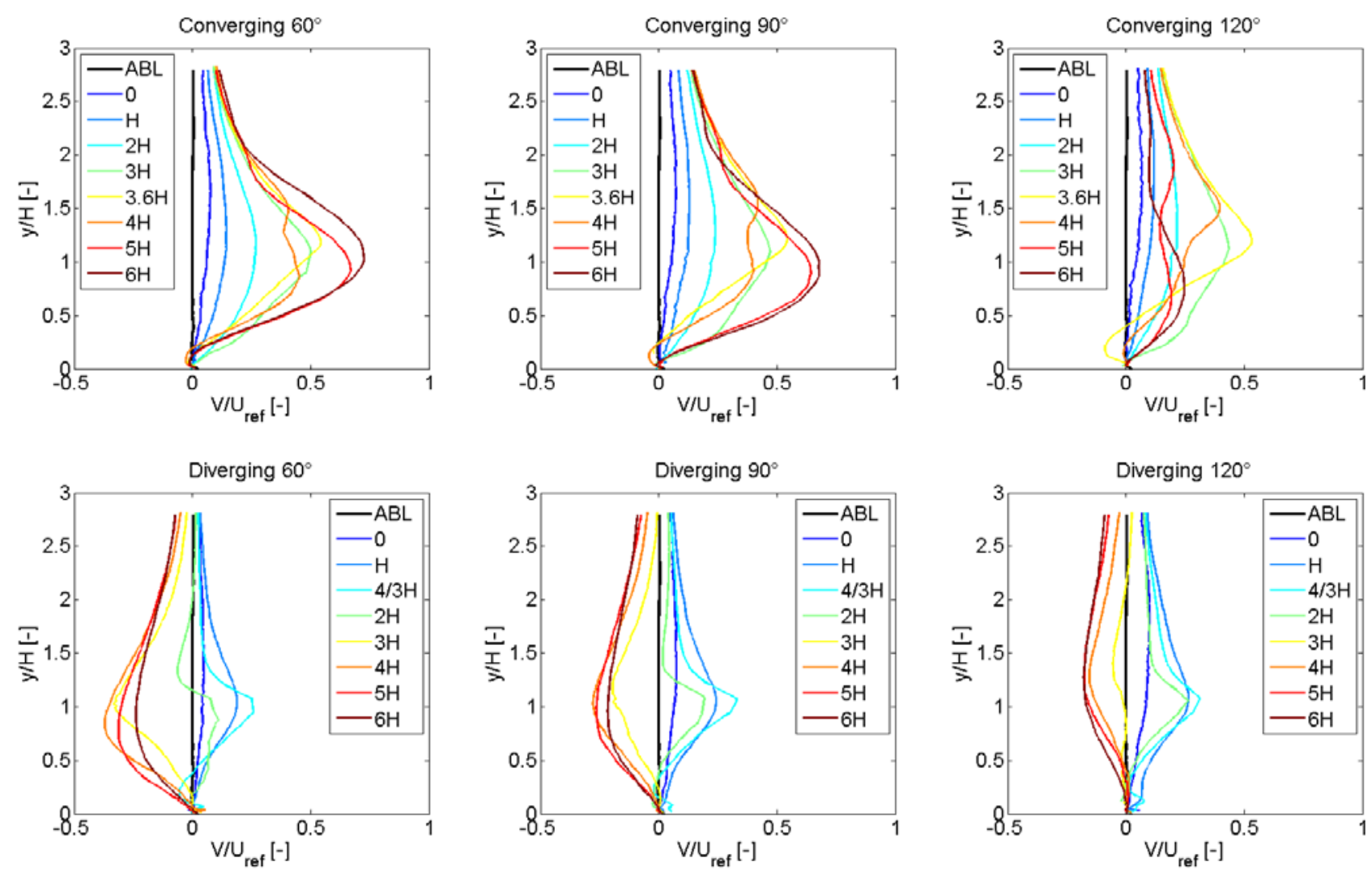

7

Figure 8: Vertical profiles of the normalized vertical velocity at 8 downstream positions for six cases. The velocities are normalized by $\mathrm{U}_{\text {ref }}$. Additionally the $\mathrm{ABL}$ profile is given.

9 As for the horizontal wind speeds also for the vertical wind speeds vertical profiles are given besides the horizontal profiles. These profiles are given in Figure 8 for all 6 converging and diverging cases at different downstream locations. Also the vertical profiles are normalized with $U_{\text {ref. }}$ The vertical velocities are approximately zero in the ABL, because the flow in the ABL is horizontal. As already discussed rather high upwards motions can be found in all of the cases. The upwards motions are in general stronger for the converging compared to the diverging cases leading to the high- 
1 er vertical flow rates at roof height reported by Blocken et al. [22] and Li et al. [24]. For the con-

2 verging cases only upwards motions can be found, while for the diverging cases there are upwards 3 and downwards motions. For all cases the upwards motions are increasing from the ground up to 4 about the roof heights and then decreasing again. The increase is caused by the decreasing effect of 5 the horizontal ground on the flow and the decrease is cause by the fact that there is no blockage by 6 buildings above the roof height.

7 For the converging cases the vertical motions are smaller for larger angles between the buildings, especially for the case with $120^{\circ}$ compared to the case with $90^{\circ}$. The results in Figure 8 confirm, what was discussed in Figure 4 and 7. The vertical velocities increase upstream of the narrowest passage, where they slightly decrease and continue increasing downstream of the passage. On the other hand for the diverging cases the upwards motions decrease after the narrowest passage and further downstream downwards motions can be found. The shape of the vertical profiles close to the narrowest passage is different from most of the profiles. A stronger peak can be found at roof height.

The results of this section can be summarized as follows. There are strong upwards motions for all studied cases (already shown for the converging cases by Blocken et al. [22] and Li et al. [24]). Due to these upwards motions a part of the air is flowing over the buildings instead of through the passage between the buildings and therefore the Venturi effect is not as strong as suggested by literature (e.g. [19]). This effect was first descript by Blocken et al. [21, 22], who called this the windblocking effect. The upwards motions upstream of the narrowest passage between the buildings are stronger for converging compared to diverging cases, what explains partly the lower wind speeds in the passage between the buildings. These upwards motions could have a positive effect on the local air quality and thermal comfort, due to increased removal of heat and pollutants from the pedestrian level. 
1

2

3

4

5

\subsubsection{Turbulence}

Besides the wind speeds also the turbulence level has an impact on the human comfort, heat removal and local wind power potential. Therefore in a last part of this paper the results of the measured 4 turbulence are discussed. Li et al. [24] did not report any results related to turbulence, while Blocken et al. [21] reported turbulence intensities, but did not discuss the results in detail.
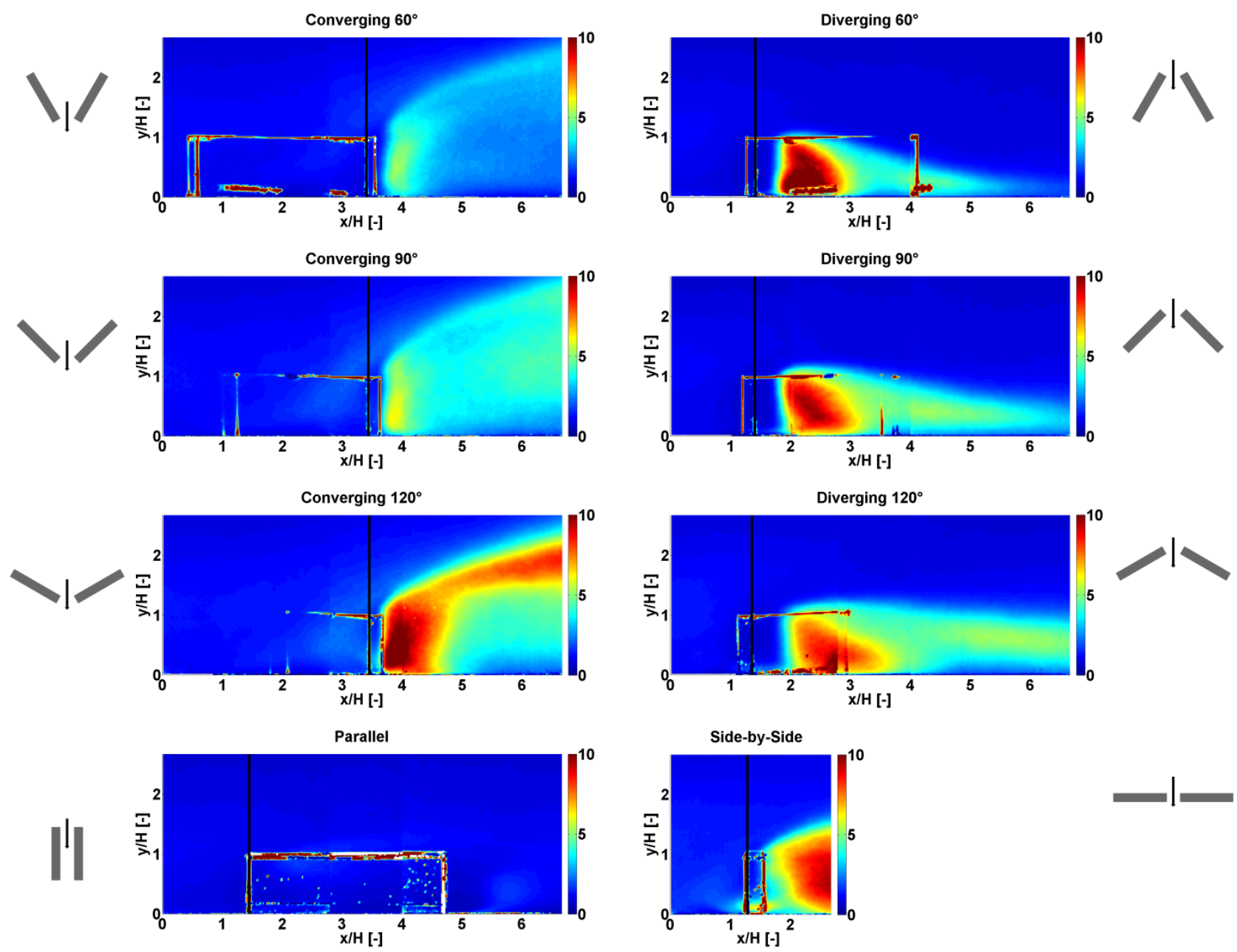

Figure 9: Normalized turbulent kinetic energies for all 8 studied cases. The turbulent kinetic energies are normalized by $\mathrm{TKE}_{\text {ref. }}$ The black line indicates the position of the narrowest passage between the buildings.

9 Figure 9 presents the normalized turbulent kinetic energies (TKE) for all eight studied cases. The results are normalized by the value measured without the buildings at roof height at the position of the narrowest passage between the buildings $\left(\mathrm{TKE}_{\mathrm{ref}}=0.185 \mathrm{~m}^{2} / \mathrm{s}^{2}\right)$. A strong increase of the turbu- 
1 lence can be found due to the buildings. For some cases the turbulence is increased by about a fac-

2 tor of ten after the narrowest passage. The turbulence level is overall slightly lower for the converg-

3 ing compared to the diverging cases. For the converging cases the turbulent kinetic energy is in-

4 creasing with increasing angles between the buildings. Most of the turbulent kinetic energy is pro-

5 duced in the regions with strong streamwise velocity gradients just after the narrowest passage (see

6 also Figure 11). Further downstream the turbulent kinetic energy only reaches high values above the

7 roof level. For the diverging cases most of the turbulent kinetic energy after the narrowest passage

8 between the buildings, where there are the highest streamwise velocity gradients. The turbulence

9 level is increasing for smaller angles between the buildings. For the diverging cases downstream of

10 the passage the highest turbulent kinetic energies is can be found close to the ground.

11 For the case with the parallel buildings the turbulence level is much lower compared to the converg12 ing and diverging configurations. The flow is less disturbed by the parallel buildings due to the low blockage. For the side-by-side configuration the turbulence is produced downstream of the buildings and the peak is not in the field of view of the measurement.

From the results presented in Figure 9 it can be concluded that the turbulence has a stronger impact on the human comfort in the case of diverging building geometries, because the highest turbulence level can be found between the buildings, where the pedestrians are, compared to the converging cases, where the highest turbulence levels can be found downstream of the buildings. Also the turbulence is located at the pedestrian level. For the converging configurations the turbulence can mainly be found downstream of the buildings and above the pedestrian level. 

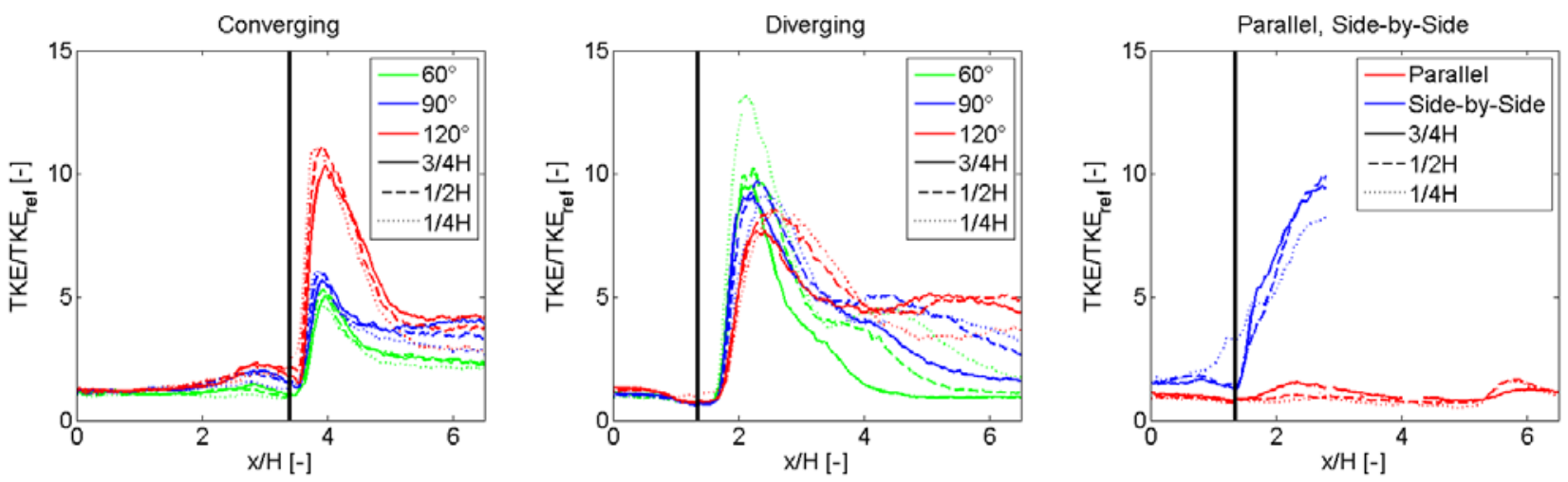

2 Figure 10: Horizontal profiles of the turbulent kinetic energy at three heights above the ground for all eight cases. The turbulent kinetic energyies are normalized by $\mathrm{TKE}_{\text {ref. }}$ The vertical line indicates the position of the narrowest passage.

4 In Figure 10 profiles of the normalized turbulent kinetic energy are given for all cases. The turbu-

5 lent kinetic energies are normalized by $\mathrm{TKE}_{\text {ref. }}$ For all cases the turbulence level is strongly in-

6 creased due to the buildings and the turbulent kinetic energies are lowest upstream of the buildings

7 and in the passage between the buildings. For the parallel buildings the turbulence level is every-

8 where rather low. For all the other cases there is a strong increase of the turbulence level down-

9 stream of the narrowest passage, where there are the largest streamwise velocity gradients. The turbulent kinetic energies are only slightly increasing towards the ground. The turbulent kinetic energies are increasing with larger angles between the buildings for converging configurations. For diverging configurations the turbulent kinetic energies are decreasing with increasing angles between the buildings. 

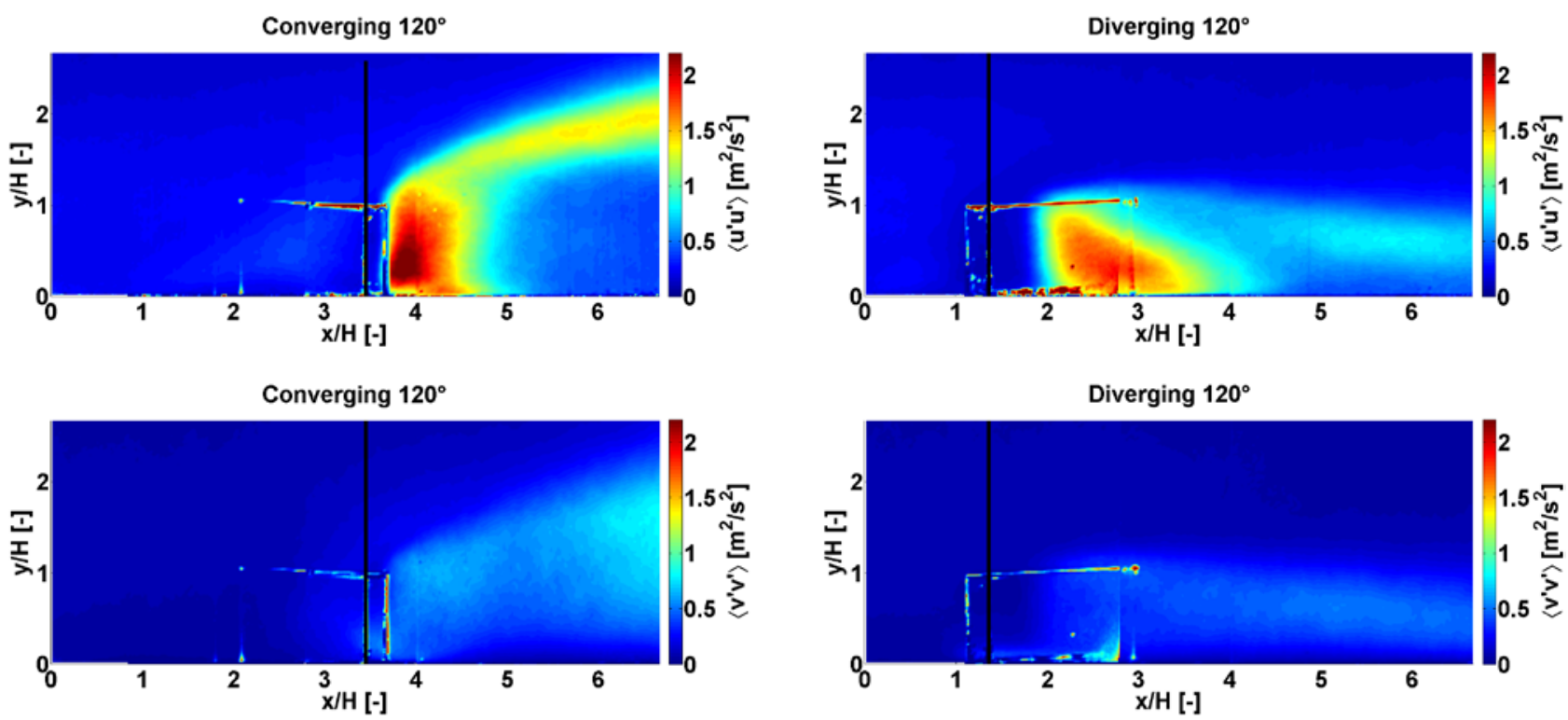

Figure 11: Reynolds stresses $\left(\left\langle\boldsymbol{u}^{\prime} \boldsymbol{u}^{\prime}\right\rangle\right.$ and $\left.\left\langle\boldsymbol{v}^{\prime} \boldsymbol{v}^{\prime}\right\rangle\right)$ for two studied cases. The black line indicates the position of the narrowest passage between the buildings.

Finally the Reynolds stresses are analysed. Only three (of six) Reynolds stresses can be determined from a planer PIV measurement $\left(\left\langle\boldsymbol{u}^{\prime} \boldsymbol{u}^{\prime}\right\rangle,\left\langle\boldsymbol{v}^{\prime} \boldsymbol{v}^{\prime}\right\rangle\right.$ and $\left.\left\langle\boldsymbol{u}^{\prime} \boldsymbol{v}^{\prime}\right\rangle\right)$. Because the shear in the flow is rather low the shear stresses $\left\langle\boldsymbol{u}^{\prime} \boldsymbol{v}^{\prime}\right\rangle$ are very low compared to the normal stresses $\left(\left\langle\boldsymbol{u}^{\prime} \boldsymbol{u}^{\prime}\right\rangle\right.$ and $\left.\left\langle\boldsymbol{v}^{\prime} \boldsymbol{v}^{\prime}\right\rangle\right)$ in the symmetry plane and therefore the results of the shear stresses are not presented here. The normal stresses $\left(\left\langle\boldsymbol{u}^{\prime} \boldsymbol{u}^{\prime}\right\rangle\right.$ and $\left.\left\langle\boldsymbol{v}^{\prime} \boldsymbol{v}^{\prime}\right\rangle\right)$ are given in Figure 11 for two studied cases. These two cases were chosen, because they have similar turbulence levels. For both cases $\left\langle\boldsymbol{v}^{\prime} \boldsymbol{v}^{\prime}\right\rangle$ is much smaller compared to $\left\langle\boldsymbol{u}^{\prime} \boldsymbol{u}^{\prime}\right\rangle$. Therefore the turbulence is not isotropic and $\left\langle\boldsymbol{u}^{\prime} \boldsymbol{u}^{\prime}\right\rangle$ is the most important component for the turbulent kinetic energy. This means that RANS (Reynolds-averaged Navier-Stokes) CFD model, which assume isotropy, should not be used to simulate flows around these types of building configurations, as they cannot capture the anisotropy. Furthermore, for the converging case it can be observed in detail, in a region close to the ground and just upstream the passage, that the term $\left\langle\boldsymbol{u}^{\prime} \boldsymbol{u}^{\prime}\right\rangle$ slightly decreases while $\left\langle\boldsymbol{v}^{\prime} \boldsymbol{v}^{\prime}\right\rangle$ increases. Since this effect is expected when the flux is contracted, it can be deduced from Figure 11 that the Venturi effect is confined to that small region and could explain the increase of velocity that happens at pedestrian level. 
1

2

3

4

5

6

7

8

9

\section{Discussion}

Wind tunnel measurements were conducted for two neighbouring buildings with different angular configurations. Additional measurements are needed to better understand the flow between two buildings for a larger range of configurations. Due to practical reasons planer PIV in the symmetry plane were conducted instead of stereoscopic or tomographic PIV. Therefore important threedimensional effects could not be measured. These effects could be studied with CFD simulations (e.g. $[22,24])$. This study was conducted with a constant wind direction, which was parallel to the symmetry plane. To get more realistic and representative results the flow fields should be measured for different wind directions. To measure additional wind directions with PIV, not only the wind tunnel models, but also the camera and the light sheet have to be turned. Additionally stereoscopic PIV would be needed to measure the out of plane components. Blocken et al. [21] could measure different wind directions with hot-wire anemometry, but the spatial resolution was lower compared to PIV and only the velocity magnitude and not the components could be measured. This study was conducted for one specific ABL. To get more general results the measurements could be repeated for different $\mathrm{ABL}$.

Also changes in the building geometries and configurations could add valuable information on flows between buildings. First of all the building geometries itself could be changed. For example taller, wider or longer buildings could be used. Or different distances between the buildings could be used. A number of additional configurations were already studied by Blocken et al. [21, 22] and Li et al. [24]. The two buildings could also have different geometries. One of the two buildings could be taller, longer or wider than the second building. The measurements could also be repeated with additional buildings. Finally buoyancy could have an important impact on the flow for weather conditions with low wind speeds and high surface temperatures. The upwards motions could be increased due to buoyancy.

\section{Conclusion}


1 The flow between two buildings with different angular configurations was measured in the wind tunnel. The wind speed in the passage between two buildings are for all cases and all heights above the ground higher for diverging compared to converging configurations. This was first shown by Blocken et al. $[21,22]$ at the pedestrian level for $90^{\circ}$ angles between the buildings. The results of this paper show that the highest wind speeds at all heights above the ground in the passage between two buildings can be found for diverging configurations with small angles between the buildings. For parallel configurations the wind speeds are lower compared to diverging cases with small angles. The wind speeds are also decreasing for buildings which are built side-by-side and decreasing angles between the buildings for converging configurations. Blocken et al. [21, 22] explained these effects by the fact that part of the air is not flowing thought the passages between the buildings but is flowing over the buildings. This is confirmed here by the fact that the upwards motions upstream of the narrowest passage is stronger for the converging compared to the diverging configurations. The results of this study also show that the shapes of the vertical profiles of velocity are strongly changing between the buildings. Upstream of the narrowest passages the profiles resemble an atmospheric boundary layer profile and at the narrowest passages the velocities are rather constant over height between the buildings.

For both the converging and diverging configurations the highest turbulence production is found for the cases with highest wind speeds in the narrowest passage. The regions with the highest turbulent kinetic energies are for all cases located downstream of the narrowest passage. The Reynolds stresses show that the turbulence is not isotropic and the horizontal normal stresses are the dominant Reynolds Stresses. Considering changes in wind speeds and turbulence levels are important, when new buildings are designed to achieve a high pedestrian wind comfort and to remove heat and pollution from the pedestrian level. The increased wind speeds in the passage between the buildings and the increased turbulence level downstream of the passage can lead to decreased pedestrian wind comfort. Based on this study and the studies by Blocken et al. [21, 22], the most critical case for the 
1 wind comfort is a diverging building configuration with small angles between the buildings. For

2 this configuration the highest wind speeds can found in the narrowest passage and shortly downstream of this passage. Further the turbulence levels at the pedestrian level downstream of the narrowest passage are highest for this case. The regions with the highest wind speeds and turbulences levels are therefore located between the buildings. For the converging cases these regions are found downstream of the buildings. The probability that pedestrians are present between the buildings is mostly higher compared to downstream of the buildings. Turbulence could also help to improve the air quality due to the better mixing with the air above the buildings. For the converging cases upwards motions are found between the buildings. These upwards motions could increase the removal of heat and pollutants. The higher wind speeds close to the roof level for the diverging configurations with small angles between the buildings could also increase the local potential for wind power generation. All these effects should be taken into consideration, when groups of buildings are constructed.

\section{Acknowledgments}

The second author would like to thank to the public institutions form Uruguay, CSIC (I+D Grupos 2014) and ANII (POS_NAC_2014_1_102857), for their financial support. The authors would also like thank Prof. Bert Blocken for the very helpful discussions and advices during the design of the measurements.

\section{References}

[1] Mochida A., Lun I. Y.F., 2008. Prediction of wind environment and thermal comfort at pedestrian level in urban area. Journal of Wind Engineering and Industrial Aerodynamics 96, 1498-1527.

[2] Blocken B., Stathopoulos T., 2013. CFD simulation of pedestrian-level wind conditions around buildings: Past achievements and prospects. Journal of Wind Engineering and Industrial Aerodynamics $121,138-145$. 
1 [3] Wiren B. G., 1975. A wind tunnel study of wind velocities in passages between and through

2 buildings. Proc., 4th Int. Conf. on Wind Effects on Buildings and Structures, Cambridge University

3 Press, Cambridge, U.K., 465-475.

4 [4] Beranek W.J., 1984. Wind environment around single buildings of rectangular shape, HERON, $5 \quad$ Vol.29, No.1, IBBC-TNO, Delft.

6 [5] Stathopoulos T., Storms R. 1986. Wind environmental conditions in passages between build7 ings. Journal of Wind Engineering and Industrial Aerodynamics 24, 19-31.

8 [6] Tsang C.W., Kwok K.C.S., Hitchcock P.A., 2012. Wind tunnel study of pedestrian level wind 9 environment around tall buildings: Effects of building dimensions, separation and podium. Building and Environment 49, 167-181.

[7] Dutt A.J., 1991. Wind flow in an urban environment. Environ. Monit. Assess. 19, 495-506.

[8] Stathopoulos, T.2006. Pedestrian-level winds and outdoor human comfort. Journal of Wind Engineering and Industrial Aerodynamics 94 (11), 769-780.

[9] Blocken, B., Carmeliet, J., Stathopoulos T., 2007. CFD evaluation of wind speed conditions in passages between parallel buildings - effect of wall-function roughness modifications for the atmospheric boundary layer flow. Journal of Wind Engineering and Industrial Aerodynamics 95, 941962.

[10] Rizk, A.A., Henze G., 2010. Improved airflow around multiple rows of buildings in hot arid climates. Energy and Buildings 42, 1711-1718.

[11] Tutar, M., Oguz G., 2002. Large eddy simulation of wind flow around parallel buildings with varying configurations. Fluid Dynamics Research 31, 289-315.

[12] Hong, B., Lin B., 2015. Numerical studies of the outdoor wind environment and thermal comfort at pedestrian level in housing blocks with different building layout patterns and trees arrangement. Renewable Energy 73, 18-27. 
1 [13] Asfour, O.S., 2010. Prediction of wind environment in different grouping patterns of housing

2 blocks. Energy and Buildings 42, 2061-2069.

3 [14] Awan, M.R., Riaz, F., Nabi Z., 2015. Analysis of conditions favourable for small vertical axis

4 wind turbines between building passages in urban areas of Sweden, International Journal of Sus-

$5 \quad$ tainable Energy http://dx.doi.org/10.1080/14786451.2015.1037839 .

6 [15] Simoes, T., Estanqueiro, A., 2016. A new methodology for urban wind resource assessment.

$7 \quad$ Renewable Energy 89, 598-605.

8 [16] Li Q.S., Chen F.B., Li Y.G., Lee Y.Y., 2013. Implementing wind turbines in a tall building for 9 power generation: A study of wind loads and wind speed amplifications. Journal of Wind Engineering and Industrial Aerodynamics 116, 70-82.

[17] Kubilay, A., Derome, D., Blocken, B., Carmeliet, J., 2014. Numerical simulations of winddriven rain on an array of low-rise cubic buildings and validation by field measurements. Building and Environment 81, 283-295.

[18] Reiter S., 2010. Assessing wind comfort in urban planning. Environment and Planning B: Planning and Design 37, 857-873.

[19] Gandemer, J.,1975. Wind environment around buildings: Aerodynamic concepts, in: Proceedings of the 4th International Conference on Wind Effects on Buildings and Structures, Heathrow, UK.

[20] Lawson, T. V., 1980. Wind effects on buildings, Vol. 1, Applied Science Publishers Ltd., London.

[21] Blocken B., Stathopoulos T., and Carmeliet J., 2008. Wind Environmental Conditions in Passages between Two Long Narrow Perpendicular Buildings. Journal of Aerospace Engineering 21 (4), 280-287. 
1 [22] Blocken, B., Moonen, P., Stathopoulos, T., and Carmeliet, J., 2008. A numerical study on the

2 existence of the Venturi-effect in passages between perpendicular buildings. Journal of Engineering

3 Mechanics - ASCE 3114 (12), 1021-1028.

[23] Venturi G.B. 1799. Experimental Enquiries Concerning the Principle of the Lateral Communication of Motion in Fluids: Applied to the Explanation of Various Hydraulic Phenomena, Translated from the French by W. Nicholson, 1st English Ed., J. Taylor, Architectural Library, HighHolborn, London.

[24] Li B., Luo Z., Sandberg M., and Liu J., 2015. Revisiting the 'Venturi effect' in passage ventilation between two nonparallel buildings. Building and Environment 94, 714-722.

[25] Gerhardt H.J., Kramer C., 1991. Wind climate in city centres: Pedestrian comfort versus accumulation of pollutants. Journal of Wind Engineering and Industrial Aerodynamics 38, 131-139.

[26] Blocken B., Persoon J., 2009. Pedestrian wind comfort around a large football stadium in an urban environment: CFD simulation, validation and application of the new Dutch wind nuisance standard. Journal of Wind Engineering and Industrial Aerodynamics 97, 255-270.

[27] Keane R.D., Adrian R.J., 1990. Optimization of particle image velocimetry. Part I: Double pulsed systems. Meas Sci Technol 1(11), 1202-1215.

[28] Bolinder J., 1999. On the accuracy of a digital particle image velocimetry system. Technical Report. Lund Institute of Technology, Sweden.

[29] Prasad A.K., 2002. Particle image velocimetry. Current Science 79 (1), 51-60.

[30] International Towing Tank Conference (ITTC), 2008. Uncertainty analysis: particle image velocimetry, 7.5-01-03-03,1-12.

[31] Irwin, H., 1981. The Design of Spires for Wind Simulation. Journal of Wind Engineering and Industrial Aerodynamics 7(3), 361-366. 
1 [32] Counihan, J., 1969. An Improved Method of Simulating an Atmospheric Boundary Layer in a

2 Wind Tunnel. Atmospheric Environment 3 (2), 197-214.

3 [33] Snyder, W.H., 1981. Guideline for fluid modeling of atmospheric diffusion. Rep. No. EPA-

4 600/8-81-009, U.S. Environmental Protection Agency, US.

5 [34] VDI, 2010. Environmental meteorology; Physical modelling of flow and dispersion processes

6 in the atmospheric boundary layer, application of wind tunnel. VDI 3783, Beuth Verlag GmbH,

7 Berlin; Germany. 